\title{
Assessment of Selected ECG Voltage Criteria for Abnormality in Eccentric and Concentric Left Ventricular Hypertrophy
}

\author{
F U Huwez, P W Macfarlane \\ University of Glasgow, Scotland
}

\begin{abstract}
The effect of left ventricular volume ( $L V V)$ in relation to the left ventricular mass (LVM) was studied on the voltage electrocardiographic (ECG) criteria of left ventricular hypertrophy (LVH). For this purpose, the sensitivity of numerous voltage criteria were assessed in patients with documented echocardiographic (echo) $\mathrm{LVH}$ with or without left ventricular dilatation.

The ECG criteria that combined voltages in two leads were more sensitive than when a single voltage criterion was utilized. There was no characteristic pattern of increased voltages to differentiate between eccentric and concentric subtypes of LVH. However, the Cornell criteria were less affected by the LV geometry for detecting $L V H$ with or without LV dilatation. This is probably due to the fact that they utilize the voltages in a precordial and a limb lead.
\end{abstract}

\section{Introduction}

It is well recognized that there are numerous physiological and pathological factors that affect ECG criteria for left ventricular hypertrophy (LVH) [1]. In 1960, Allenstein and Mori evaluated ECG criteria that were introduced for the diagnosis of $\mathrm{LVH}$ and they noticed that the literature at that time included over 30 ECG criteria [2]. However, in clinical practice, voltage criteria are the most commonly used despite the evidence that voltage ECG-LVH criteria are influenced by many factors that might commonly co-exist with LVH. For example, there is evidence that increased left ventricular volume (LVV) might potentiate the QRS voltages [3,4]. Therefore, it might be expected that the ECG-LVH voltage criteria would be more positive in LVH with LV dilatation than in LVH with normal LVV.

\section{Methods}

Consecutive patients attending the echocardiography laboratory in Glasgow Royal Infirmary were recruited to the study provided that they had documented echo LVH in the absence of hypertrophic obstructive cardiomyopathy, bundle branch block, pericardial disease, kyphoscoliosis or emphysema, or history of myocardial infarction. The ECGs were recorded by a Siemens Mingorec 4 or by a computer compatible electrocardiograph designed locally [5]. The amplitudes of the QRS voltages were measured by a computer program described elsewhere [6]. All the amplitudes were also checked manually and were compared to age and sex dependent normal limits that were derived from an earlier study from our department [7]. The sensitivity of the following ECG-LVH voltage criteria was assessed in the two groups of echo LVH:

1. Cornell voltage criteria [8]: $\mathrm{SV} 3+\mathrm{RaVL}>2.8 \mathrm{mV}$ in men and $>2.0 \mathrm{mV}$ in women,

2. Sokolow-Lyon precordial voltage criteria [9]: SV1 + $\mathrm{RV} 5$ or $\mathrm{RV} 6 \geq 3.5 \mathrm{mV}$

3 . Isolated voltage criteria included in the Romhilt-Estes point scoring system [10] including SV1 or SV2 $\geq 3.0$ $\mathrm{mV}, \mathrm{RV} 5$ or $\mathrm{RV} 6 \geq 3.0 \mathrm{mV}$ and $\mathrm{R} \mathrm{I}$ or RaVL $\geq 2.0 \mathrm{mV}$

The echocardiographic examinations were undertaken with a Diasonics 3400 Cardiovue phased imaging system as described in a previous study [11]. The M-mode echo dimensions of the left ventricle (LV) were used to calculate left ventricular mass (LVM) according to the Penn convention [12] but left ventricular volume (LVV) was estimated using the equation of Pombo et al [13]. Both the derived echo LVM and LVV were indexed to body surface area (BSA) according to the formula of DuBois and DuBois [14]. Patients with echo LVH were defined by echo LVM indexed to BSA exceeding 131 $\mathrm{g} / \mathrm{m}^{2}$ in men and $109 \mathrm{~g} / \mathrm{m}^{2}$ in women [15]. LVV indexed to BSA (LVVI) exceeding $90 \mathrm{ml} / \mathrm{m}^{2}$ identified those patients with LVH and LV dilatation [13]. Based on one of our earlier studies [11], concentric LVH was defined as increased LVM indexed to BSA in the presence of a normal or even reduced LVV (indexed to BSA), while patients with eccentric LVH were identified when LVH was associated with left ventricular dilatation.

\section{Results}

36 patients completed the study including 25 men and 11 women. They had a mean age of 54.6 years and an age range of 30-72 years. The underlying pathological conditions included hypertension in 28 patients and 
coronary artery disease without myocardial infarction (MI) in 8 patients. Their echo data were as follows:

(1) Concentric LVH: 19 patients with mean LVMI $196.0+64 \mathrm{~g} / \mathrm{m}^{2}$ ( range 116 to $339 \mathrm{~g} / \mathrm{m}^{2}$ ) and a mean LVVI of $52.3 \pm 19.2 \mathrm{ml} / \mathrm{m}^{2}$ ( range 25 to $\left.90 \mathrm{ml} / \mathrm{m}^{2}\right)$.

(2) Eccentric LVH: 17 patients with a mean LVMI $220.8 \pm 67.8 \mathrm{~g} / \mathrm{m}^{2}$ ( range 139 to $344 \mathrm{~g} / \mathrm{m}^{2}$ ) and a mean LVVI $143.3 \pm 42.9 \mathrm{~m} / \mathrm{m}^{2}$ ( range 91 to 238 $\left.\mathrm{ml} / \mathrm{m}^{2}\right)$.

The sensitivities of the ECG-LVH voltage criteria are shown in table 1 . The isolated limb and precordial voltage criteria $\mathrm{RI}$ or $\mathrm{RaVL} \geq 2.0 \mathrm{mV} ; \mathrm{SV} 1$ or $\mathrm{SV} 2 \geq 3.0$ $\mathrm{mV}$; and RV5 or RV6 $\geq 3.0 \mathrm{mV}$ which constitute a major component of the Romhilt-Estes point scoring system [10] were the least sensitive in detecting LVH. However, patients with concentric LVH had positive ECG criteria $\mathrm{RI}$ or $\mathrm{RaVL}>2.0 \mathrm{mV}$ four and half times more frequently than those with eccentric LVH, with sensitivities of $9 \%$ and $2 \%$ respectively. In comparison to the precordial voltages, the $\mathrm{R}$ wave amplitude in leads $\mathrm{I}$ and aVL are less likely to be affected by the proximity of the heart to the chest wall. The combination of precordial voltage criteria had a higher sensitivity in detecting LVH. The sensitivity for the Cornell criteria was $51 \%$ for both types of echo LVH while the sensitivity of the Sokolow- Lyon precordial voltage criteria for concentric LVH was $51 \%$ compared to a lower sensitivity of $39 \%$ for eccentric LVH. Neither of the combination voltage criteria was able to differentiate between the two types of echo LVH.

Table 1. Sensitivities of various ECG voltage criteria in the two echocardiographic types of LVH

$\begin{array}{lll}\begin{array}{l}\text { Type of LVH } \\ \text { SV1/SV2 } \\ (\geq 3.0 \mathrm{mV})\end{array} & \begin{array}{l}\text { Concentric } \\ \text { RV5/RV6 } \\ (\geq 3.0 \mathrm{mV})\end{array} & \begin{array}{l}\text { Eccentric } \\ 14 \%\end{array} \\ \begin{array}{l}\mathrm{RI} / \mathrm{RaVL} \\ (\geq 2.0 \mathrm{mV})\end{array} & 9 \% & 14 \% \\ \begin{array}{l}\mathrm{SV} 1+\mathrm{RV} 5 / \mathrm{RV} 6 \\ (\geq 3.5 \mathrm{mV})\end{array} & 55 \% & 2 \% \\ \begin{array}{l}\text { Cornell } \\ \text { ( }\end{array} & 51 \% & 39 \% \\ & & 51 \%\end{array}$

*Cornell voltage criteria : SV3 + RaVL $>2.8 \mathrm{mV}$ in men and $>2.0 \mathrm{mV}$ in women.

\section{Discussion}

Brody [3] in his theoretical model suggested that increased cardiac volume potentiates QRS voltages. Later Battler et al [16] found in the conscious dog that endocardial voltage recordings have a positive correlation with changes of cardiac size while the latter had an inverse relationship with the surface ECG voltages. However, two clinical studies involving patients with chronic cardiac failure [17] and chronic renal failure treated by haemodialysis [18] suggested that cardiac size had a negative correlation with the QRS voltages. In both those studies it was observed that reduction in cardiac size was associated with increased QRS voltages. However, Rudy et al [19] have demonstrated that the presence of fluid in the lungs may adversely affect the QRS voltages. The controversies arising from these experimental and clinical studies in relation to the role of cardiac size on the QRS voltages remained a focus of interest to us.

In this study, we could not demonstrate convincingly that $\mathrm{LV}$ dilatation in the presence of $\mathrm{LVH}$ would result in increased sensitivity of the QRS voltages. The reasons are not clear but a possible explanation is the variability of the intra-thoracic volume conductor inhomogeities among the individuals of the study population. If the role of the latter factor is to be eliminated, it may be possible to show a positive correlation between cardiac volume and QRS complexes. Indeed, we have shown earlier [21] that QRS voltages were reduced significantly in the early postoperative period following valve replacement for volume overload (aortic and mitral incompetence) while in comparison, there was a lack of such reductions in pressure overload patients (aortic stenosis). The latter finding could only be attributed to a dramatic reduction in $\mathrm{LV}$ volume that occurs after successful valve replacement for aortic incompetence [22] or mitral regurgitation [23] shortly after the operation.

However, this study did not show a different pattern of ECG- LVH in eccentric and concentric LVH, i.e. LVH with or without dilatation. Nonetheless, in a sample of a cardiac population with echo $\mathrm{LVH}$, this study confirms that ECG voltage criteria that combine voltages in two leads are more sensitive than a single voltage criterion. In addition, different LV geometry in the presence of LVH is associated with variable voltage expressions and hence there is a need for the utilization of many criteria in a point scoring system. Furthermore, the Cornell criteria are less affected by the LV geometry in detecting LVH with or without LV dilatation and this is probably due to the fact that they utilize the voltages in a precordial and a limb lead.

\section{References}

[1] Milliken JA, Macfarlane PW. Enlargement and Hypertrophy. In: PW Macfarlane, TDV Lawrie (eds), Comprehensive Electrocardiology. Oxford. Pergamon Press 1989:631-670.

[2] Allenstein B, Mori H. Evaluation of electrocardiographic diagnosis of left ventricular hypertrophy based on autopsic comparison. Circulation 1960;21:401-412. 
[3] Brody DA. A theoretical analysis of intracavitary blood mass effect on heart lead relationship. Cir Res 1956;4:731-58

[4] Rudy Y. The effects of thoracic volume conductors (inhomogeneities) on the electrocardiogram. In: Paediatric and Fundamental Electrocardiography. Plonsey R and Rudy Y (eds). Dordecht, Martinus. Nijhoff Publishing 1987:49-73.

[5] Watts MP, Shoat DB. Trends in electrocardiograph design. J IERE 1987;57:140-150.

[6] Macfarlane PW, Macfarlane DK, Podolski M, Lawrie TDV. The ECG analysis program for the Mingocare system. Electromedica 1984;52:126.

[7] Macfarlane PW, Lawrie TDV. The normal electrocardiogram and vectorcardiogram. In: PW Macfarlane, TDV Lawrie (eds), Comprehensive Electrocardiography. Oxford. Pergamon Press 1989;407-458.

[8] Casale PN, Devereux RB, Alonso DR, Campo E, Kligfield $P$. Improved sex criteria of left ventricular hypertrophy for clinic and computer interpretation of electrocardiogram. Validation with Autopsy findings. Circulation 1987;75:863871.

[9] Sokolow M, Lyon TP. The ventricular complex in left ventricular hypertrophy as obtained by unipolar precordial and limb leads. Am Heart J 1949; 67:161-168.

[10] Romhilt DW, Estes EH . A point scoring system for the electrocardiographic diagnosis of left ventricular hypertrophy. Am Heart J 1968;75:75575.

[11] Huwez FU, Pringle SD, Macfarlane PW. A new classification of left ventricular geometry in patients with cardiac disease based on M-mode echocardiography. Am J Cardiol 1992;70:681-688.

[12] Devereux RB and Reichik N. Echocardiographic determination of left ventricular mass in man. Circulation 1977;55:613-618.

[13] Pombo JF, Troy BL, Russell RO Jr. Left ventricular volumes and ejection fraction by echocardiography. Circulation 1971; 40:480-490.

[14] DuBois D and DuBois EF. A formula to estimate approximate surface area if height and weight be known. Arch Intern Med 1916;17:863-871

[15] Devereux RB, Lutas EM, Casale PN. Standardization of M-mode echocardiographic left ventricular anatomic measurements. J Am Coll Cardiol 1984;4:1222-1236.

[16] Devereux RB, Lutas EM, Casale PN. Standardization of M-mode echocardiographic left ventricular anatomic measurements. J Am Coll Cardiol 1984;4:1222-1236.
[17] Battler A, Froelicher VF, Gallagher KP et al. Effects of changes in ventricular size on regional and surface QRS amplitude in the conscious Dog. Circulation 1980;62:174-80.

[18] Ishikawa K, Berson AS, Pipberger HV. Electrocardiographic changes due to cardiac enlargement. Am Heart J 1971;81:635-43.

[19] Vitolo E, Madoi S, Palvarrini M et al. Relationship between changes in $\mathrm{R}$ wave voltages and cardiac volumes: a vectorcardiographic study during haemodialysis. J Electrocardiol 1987;20:79- 46.

[20] Rudy Y, Wood R, Plonsey R, Leibman J. The effect of high lung conductivity on electrocardiographic potentials; Results from human subjects undergoing bronchopulmonary lavage. Circulation 1982;65:440- 445.

[21] Huwez FU, Pringle SD, Macfarlane PW. QRS voltage changes after valve replacement. In: Electrocardiology 1988; H . Abel (ed). Amsterdam Excerpta Medica 1989:199-202.

[22] Kennedy JW, Doces J, Stewart DK. Left ventricular function before and following aortic valve replacement. Circulation 1977;56:944-50.

[23] Schuler G, Peterson KL, Johnson A et al. Temporal response of left ventricular performance to mitral valve surgery. Circulation 1979;59:1218-1231.

Addresses for correspondence:

\section{Dr. F.U. Huwez,}

Basildon Hospital

Nethermayne,

Basildon,

Essex SS16 5NL,

England

Farhad.Huwez@btgh-tr.nthames.nhs.uk

Professor Peter W. Macfarlane,

Section of Cardiology,

Royal Infirmary,

Glasgow G31 2ER,

Scotland

peter.w.macfarlane@clinmed.gla.ac.uk 